\title{
VARIATIONS OF ORIGIN AND DISTANCE OF AXILLARY NERVE: A DESCRIPTIVE STUDY
}

Rakate Nilesh $\mathbf{S}^{1}$, Gadekar Savita $\mathbf{H}^{2}$, Gajbhiye Vivekanand $\mathbf{M}^{3}$

${ }^{1}$ Assistant Professor, ${ }^{2}$ Associate Professor, ${ }^{3}$ Professor \& Head,

Department of Anatomy R.K.D.F Medical College hospital and Research Centre, Jatkhedi, Bhopal. M.P, India.

\section{ABSTRACT}

Background - Axillary nerve, one of the terminal branches of posterior cord of brachial plexus is more prone for injuries. Lack of proper anatomical knowledge and variations of axillary nerve leads to risk of nerve injuries. The present study describes the origin of axillary nerve, its distance of origin from tip of coracoids process. Method: Thirty brachial plexuses from fifteen formalin fixed human cadavers of both the sexes were studied by dissection method. Origin and branching pattern of axillary nerve and its distance of origin from the anteromedial aspect of tip of coracoid process \& posterolateral aspect of acromion process was recorded. Results: Out of the 30 specimens studied, axillary nerve was originating from the posterior cord of brachial plexus in $90 \%$ of specimens, remaining $10 \%$ specimens showed a common trunk of origin of axillary nerve from posterior cord of brachial plexus. The mean distance of origin of axillary nerve from the anteromedial aspect of tip of coracoid process and posterolateral aspect of acromion process is $3.98 \mathrm{~cm} \mathrm{\&} 6.30 \mathrm{~cm}$ respectively. The axillary nerve terminated into anterior and posterior branch within quadrangular space in 29 specimens. In one specimen articular branch for shoulder joint was not directly arising from axillary nerve instead it is arising from anterior branch of axillary nerve. Conclusion: In studied population Axillary nerves display variations in the origin and distance of origin. Knowledge of this variation in axillary nerve is very important to clinicians, anaesthetists and orthopaedic surgeons during surgical exploration of neck, axilla and upper arm, shoulder dislocation, infraclavicular brachial plexus block and fracture of surgical neck of humerus.

KEYWORDS: Axillary nerve; Posterior cord; Coracoid process; Acromion process.

\section{INTRODUCTION}

The brachial plexus supplies upper limb and is formed by the ventral rami of $\mathrm{C} 5, \mathrm{C} 6, \mathrm{C} 7, \mathrm{C} 8$ and $\mathrm{T} 1$ supplies motor, sensory and sympathetic fibres to the upper limb. [1] It begins from the neck then run downwards and laterally over the first rib, posterior to the clavicle and enters the axilla. The brachial plexus consists of three cords-lateral, medial and posterior. Posterior cord gives branches inferior to the clavicle. The posterior cord runs behind the second part of the axillary artery and gives off the following branches - upper subscapular nerve, thoracodorsal nerve, lower subscapular nerve, axillary nerve and then continues as a large terminal branch, the radial nerve. [2] The axillary nerve leaves the posterior wall of axilla along with posterior circumflex humeral vessels and enters the quadrangular space. The trunk of axillary nerve while passing through the quadrangular space gives a first branch to shoulder joint, there after it divides into anterior and posterior branches [3].

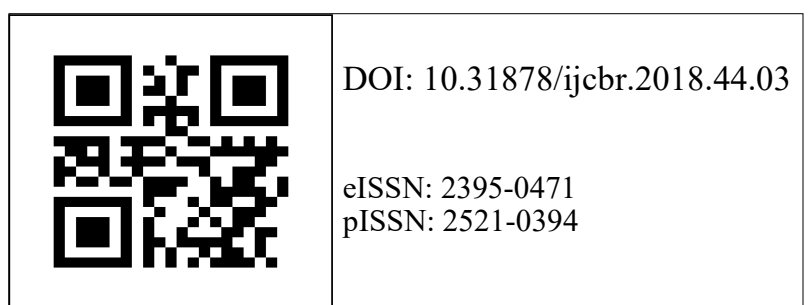

The axillary nerve is variable in its origin, course and supply to the muscles; its variations become important as it is involved fracture of surgical neck of humerus and quadrangular space syndrome. The axillary nerve is most commonly injured (6\% of all the brachial plexus injuries) during numerous orthopaedic surgeries like shoulder arthroscopy, thermal shrinkage of the shoulder capsule (excessive temperature) and plate fixation (retraction of deltoid muscle) of the proximal humerus $[4,5]$

Descriptions of nerve variations are useful in clinical/ surgical practice since an anatomical variation can be the cause of a nerve palsy syndrome due to a different relation of a nerve and a related muscle. Knowledge of variations in the branching pattern of axillary nerve from posterior cord of the brachial plexus is highly important in the surgical exploration of axilla, fracture of surgical neck of humerus, shoulder dislocation, and infraclavicular brachial plexus block.

Literature on the variations in the origin of axillary nerve from the posterior cord of the brachial plexus and its distance of origin from mid-clavicular point among Indians is scanty and altogether lacking in central Indians. The present study describes the variations in the branching pattern of axillary nerve from the pos-

Correspondence: Dr. Gadekar Savita H, Associate Professor, Department of Anatomy, R.K.D.F. Medical College Bhopal. Email: nilesh.rakate19@gmail.com 
terior cord of the brachial plexus observed in Central Indian population.

\section{MATERIALS AND METHODS}

Study design: Descriptive study

Ethics approval: Study was approved by the institutional ethics committee of our institution

Study location: Department of RKDF Medical College, Bhopal

\section{Study frame: 2 years}

Inclusion criteria: All normal cadavers of both sex and age group between 20-60 years were included for the study.

Exclusion criteria: Deformed or traumatized upper limbs were excluded from the study.

Sample size: The study was carried out on thirty upper limbs of adult human cadavers

Methodology: The gross dissection was done following the guidelines of Cunningham's manual.[5]The loose connective tissue, fat \& lymph nodes from the axilla were removed to expose its contents. The axillary artery, vein and large nerves surrounding axillary nerve were exposed. The origin of axillary nerve and its termination into anterior \& posterior divisions was observed in all the specimens. The distance of origin of axillary nerve from the anteromedial aspect of tip of coracoid process \& posterolateral aspect of acromion process was measured using vernier calliper.[6]

Statistical analysis: The data obtained was entered in Microsoft excel and analyzed using SPSS 16th version. Mean and standard deviation was calculated. The results obtained were compared with that of previous studies.

\section{RESULTS}

Out of the 30 specimens studied, axillary nerve was originating from the posterior cord of brachial plexus in $27(90 \%)$ specimens (Fig 1). The remaining $3(10 \%)$ specimens showed a common trunk of origin of axillary nerve from posterior cord of brachial plexus. It was observed that common trunk for lower subscapular \& axillary nerve. The mean distance of origin of axillary nerve from the anteromedial aspect of tip of coracoid process and posterolateral aspect of acromion process is $3.98 \mathrm{~cm} \& 6.30 \mathrm{~cm}$ respectively (Table 1 ). The axillary nerve terminated into anterior and posterior branch within quadrangular space in 29specimens. In one specimen articular branch for shoulder joint was not directly arising from axillary nerve instead it is arising from anterior branch of axillary nerve (fig.2).

\section{Table 1. Showing distance of origin of axillary nerve}

\begin{tabular}{|l|l|l|}
\hline \multicolumn{3}{|c|}{ Distance of origin of axillary nerve } \\
\hline & $\begin{array}{l}\text { Anteromedial } \\
\text { aspect of tip of } \\
\text { coracoids process }\end{array}$ & $\begin{array}{l}\text { Posterolateral } \\
\text { aspect of } \\
\text { acromion process }\end{array}$ \\
\hline Min-Max & $2.10-6.30$ & $5.10-8.60$ \\
\hline Mean $\pm S D$ & $3.98 \pm 1.05$ & $6.30 \pm 1.25$ \\
\hline
\end{tabular}

\section{DISCUSSION}

The incidence of origin of axillary nerve as a common trunk from the posterior cord of brachial plexus varies from $1 \%-22.9 \%$ in various studies. [7-11] and is summarized in Table 2. The highest incidence was reported by Rastogi [8] (22.9\%) and the lowest by Darji [10] (1\%). In the present study, its incidence is $10 \%$ which is within

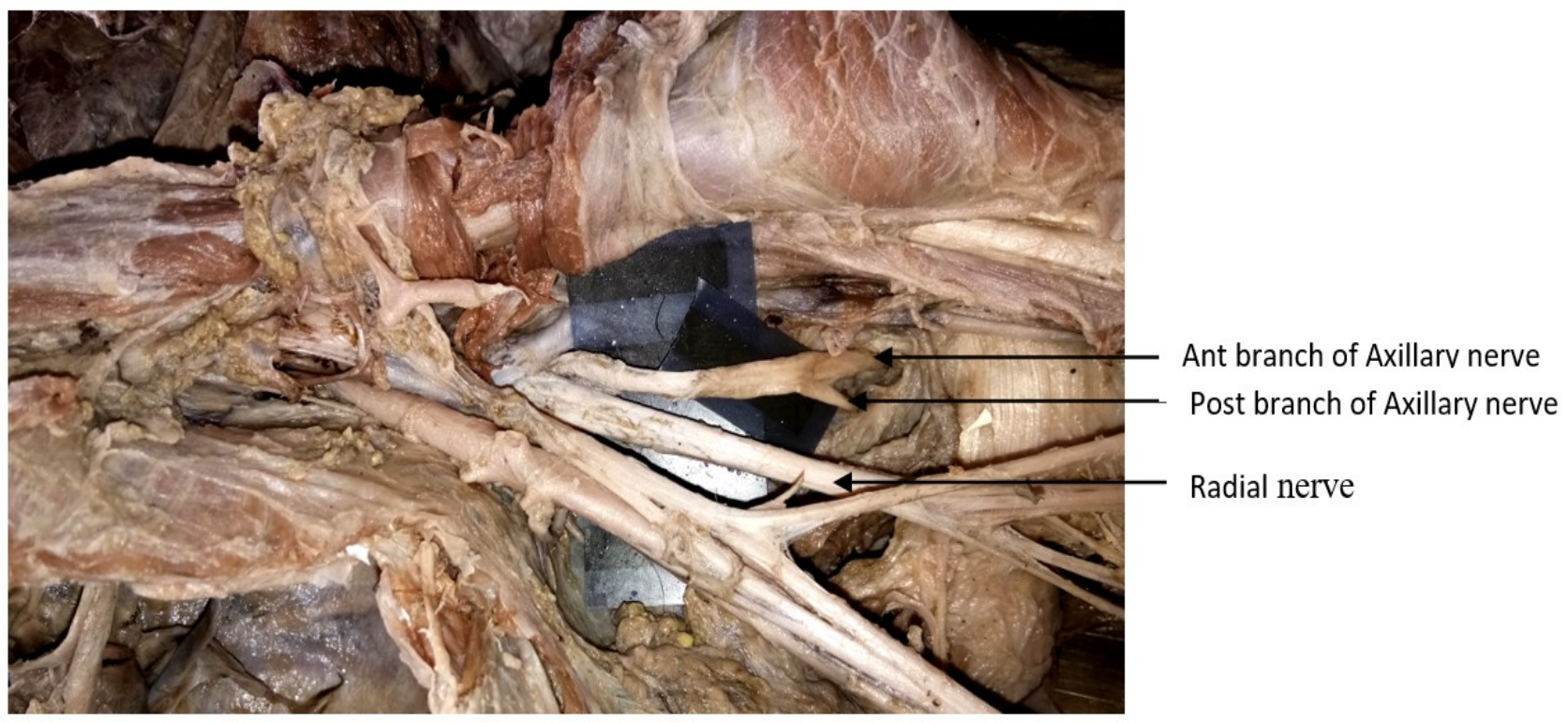

Fig 1. Showing Radial nerve Axillary nerve with anterior \& posterior division. 


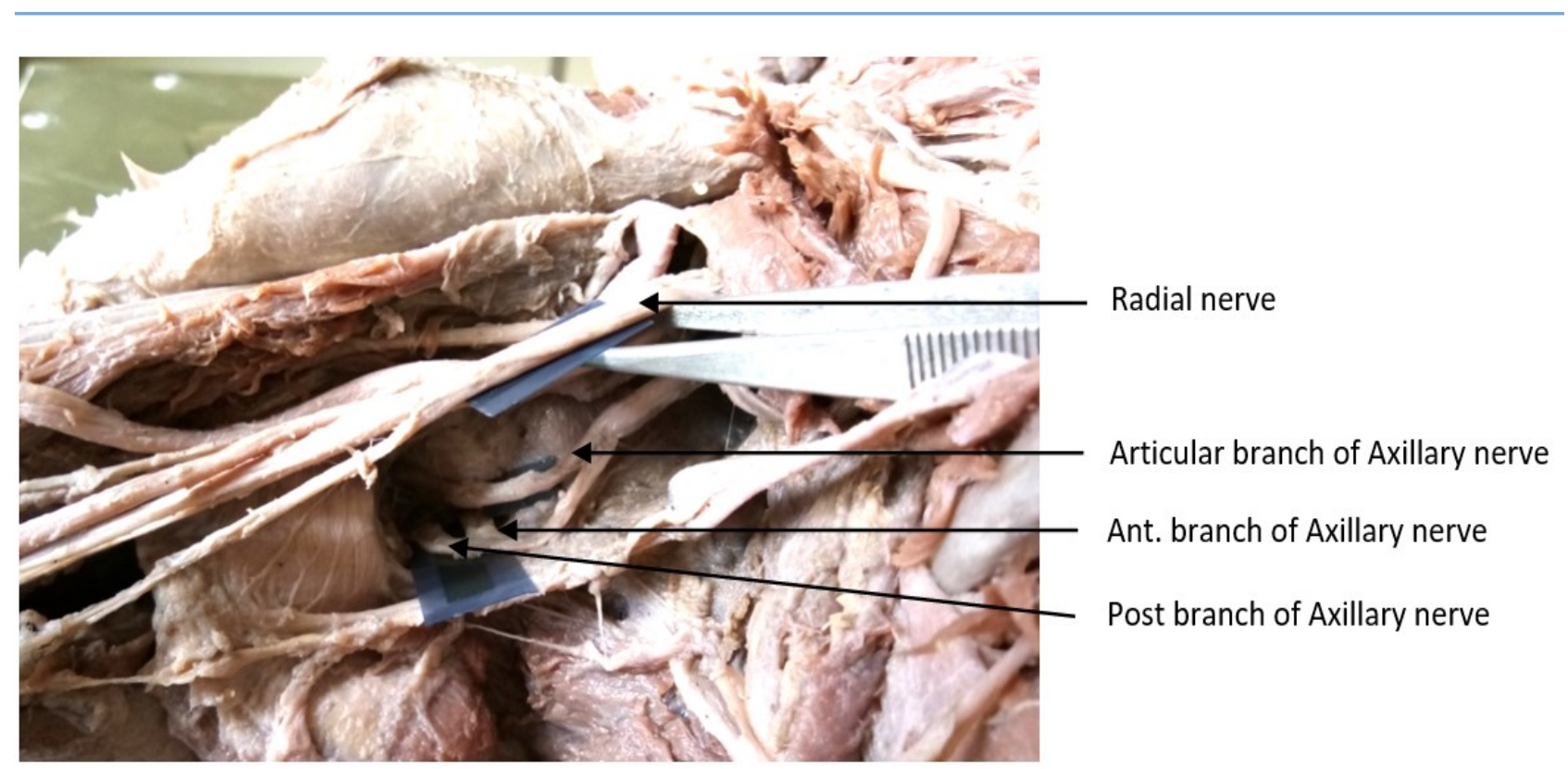

Fig 2. Showing branches of Axillary nerve

Table 2. Showing incidence of origin of axillary nerve with different authors.

\begin{tabular}{|l|l|l|l|}
\hline Author & Number of specimens & Origin from posterior cord & $\begin{array}{l}\text { Origin as a common trunk } \\
\text { from posterior cord }\end{array}$ \\
\hline Chaudhary P et al 2011[7] & 60 & $96.67 \%$ & $3.33 \%$ \\
\hline Rastogi R et al 2012 [8] & 74 & $77.10 \%$ & $22.90 \%$ \\
\hline Gaur S et al 2012 [9] & 50 & $92 \%$ & $8 \%$ \\
\hline Darji A et al 2013 [10] & 100 & $99 \%$ & $1 \%$ \\
\hline Bhosale SM et al 2014 [11] & 40 & $87.50 \%$ & $12.50 \%$ \\
\hline Present study & 30 & $90 \%$ & $10 \%$ \\
\hline
\end{tabular}

Table 3. Showing incidence of distance of axillary nerve with different authors.

\begin{tabular}{|l|l|l|l|}
\hline Author & $\begin{array}{l}\text { Number of } \\
\text { specimens }\end{array}$ & $\begin{array}{l}\text { Distance from cora- } \\
\text { coids process (cm) }\end{array}$ & $\begin{array}{l}\text { Distance from acromion } \\
\text { process }(\mathrm{cm})\end{array}$ \\
\hline Gurushantappa PK et al 2015(6) & 50 & 3.56 & 7.46 \\
\hline Burkhed WZ et al 1992 (12) & 56 & - & 5 \\
\hline Uz A et al 2007 (13) & 75 & - & 7.8 \\
\hline Tubbs RS (14) & 30 & 4 & - \\
\hline Present study & 30 & 3.98 & 6.30 \\
\hline
\end{tabular}

the range.

The mean distance of origin of axillary nerve from the anteromedial aspect of tip of coracoid

process and posterolateral aspect of acromion process of different studies [6,12-14] is compared with present study and is summarized in Tab 3.Ozgur Cetik et al [15], studied the distance of origin of axillary nerve from the acromion and its relation to arm length, and identified a safe area above the axillary nerve which is quadrangular in shape, with the length of the lateral edges is being dependent on the individual's arm length. Along its course the axillary nerve was not at the constant distance at every point from acromion.

The variations occur at the junction or separation of individual parts and may be due to an unusual formation during the development of the trunks, divisions, or cords [7].Muthoka [16] studied 75 brachial plexus in Kenyan population and found a wide range of variations in the order of branching of posterior cord. Some of his variations included a common trunk for axillary, thoracodorsal \& lower subscapular from posterior cord and a common trunk for upper, middle, lower subscapular \& axillary nerve. Axillary nerve has also been usedas a landmark for identifying the lower subscapular nerve during glenohumeral joint surgery. Gurushantappa [6] in his study of 50 specimens found that the axillary nerve gets divided into two branches anterior and posterior in Quadrangular space in $88 \%$ cases $\&$ within deltoid muscle in $12 \%$. In the present study, in all the specimens, the axillary nerve terminated into 
anterior and posterior divisions within quadrangular space. Descriptions of peripheral nerve variations are useful in clinical as well as surgical practice, since ananatomical variation can lead to nerve palsy syndromes and vascular problems. The knowledge of these variations is particularly important while diagnosing the injuries to brachial plexus, infraclavicular block procedures and surgical approaches to axillary region. Clinically, trauma of the posterior wall of the axillary region could present with a wide range of degrees of muscle impairment For instance, lesions involving common trunk for axillary nerve and thoracodorsal nerve may produce more extensive lesions including teres minor, deltoid and lattisimus dorsi muscles $[9,16]$.

The shoulder joint dislocation and rotator cuff tear causes nerve injury which is called unhappy triad of the shoulder joint. The axillary nerve is vulnerable to damage during acute trauma to the shoulder or by chronic repeated trauma like in 'quadrilateral space syndrome'(entrapment of axillary nerve). Lack of proper anatomical knowledge of nerve also leads to an increased risk of nerve injury during intramuscular injections in deltoid, intra-articular and intra-bursal steroid injections $[6,17]$.

\section{CONCLUSION}

Variations in the origin of axillary nerve from the posterior cord of brachial plexus is a common anomaly found in $10 \%$ of specimens.

Clinical importance: Knowledge of these variations is important to surgeons during surgical exploration of axilla for axillary tumours, neck during neck dissections, surgical treatment of tumours of nerve sheath such as schwannoma \& neurofibroma, shoulder dislocation\& rotator cuff tear. Furthermore, knowledge of variant anatomy of axillary nerve is of greatest importance to anaesthetists during administration of anaesthetic blocks and clinicians for interpreting effects of nerve injuries \& nerve compressions of upper limb.

\section{REFERENCES}

1) Datta AK. Superior and inferior extremities, The axilla. Essentials of human anatomy. $3^{\text {rd }}$ Ed., Kolkata: Current book international;2004:44-52.

2) O’Rahilly, R. and Müller, F. Carpenter and Swenson. Basic human anatomy: A regional study of human structure. Philadelphia W.B. Saunders Co:2008:4556

3) Standring S. Gray's anatomy. Pectoral girdle, Shoulder region, Axilla. The Anatomical basis of clinical practice. 40th Ed., London: Elsevier Churchill Livingstone; 2008:821-22.

4) Marios Loukas, Joanna Grabska, Shane Tubbs, Nihal
Apaydin, Robert Jordan. Mapping the axillary nerve within the deltoid muscle. Surgical and Radiologic Anatomy. 2009;31(3):43-47.

5) Romanes JG. Cunningham's manual of practical anatomy. The pectoral region and axilla.15 ${ }^{\text {th }} \mathrm{Ed}$. vol1.United kingdom:Oxford ;2012; 20-34

6) Gurushantappa PK, Kuppasad S. Anatomy of Axillary Nerve and Its Clinical Importance: A Cadaveric Study. Journal of clinical \& diagnostic research.2015;Mar;9(3)13-17

7) Chaudhary P, Singla R, Kalsey G, Arora K. Branching pattern of the posterior cord of brachial plexus: $A$ cadaveric study. Journal of Clinical and Diagnostic Research. 2011;5(4):787-790.

8) Rastogi R, Budhiraja V, Bansal K. Posterior Cord of Brachial Plexus and Its Branches: Anatomical Variations and Clinical Implication. Hindwai Publishing Corporation ISRN Anatomy. 2012;2013:1-3.

9) Gaur S, Katariya SK, Vaishnani H, Wani IN, Bondre $\mathrm{KV}$ et al. A cadaveric study of variation of posterior cord of brachial plexus. Int J Biol Med Res.2012;3 (3):2214-2217.

10) Darji A, Chauhan $H$, Khatri $H$, Aterkar $S$, Pensi CA.Variations in Branching Pattern of Brachial Plexus:A Cadaveric study. Int Journal of Biomedical and Advance Research. 2013;4(3):174-178.

11) Bhosale SM, Mallashetty NS. Study of variations in the origin and distance of origin of axillary nerve of the posterior cord of brachial plexus. Int J Cur Res Rev. 2014;6(15):41-44.

12) Burkhead WZ, Scheinberg RR, Box G. Surgical anatomy of the axillary nerve. J Shoulder Elbow Surg.1992;1:31-36.

13) Uz A, Apaydin N, Rozkut M, Fihan A. The anatomic branch pattern of the axillary nerve. Journal of Shoulder \& Elbow Surgery. 2007;16(2):240-44.

14) Tubbs RS, Oakes PAC, Blount JP, Salter G, et al. Surgical landmarks for the proximal portion of the axillary nerve. Journal of Neurosurgery.2001;95(6):998 $-1000$.

15) Cetik O, Uslu M, Acar HI, Comert A, Tekdemir I et al. Is there a safe area for the axillary nerve in the deltoid muscle? Journal of Bone and Joint Surgery.2006; 88-A.

16) Muthoka JM, Sinkeet SR, Shahbal SH, Matakwa LC, Ogeng'o JA. Variations in branching of the posterior cord of brachial plexus in a Kenyan population.Journal of Brachial Plexus and Peripheral Nerve Injury. 2011;6:1

17) Apaydin N, Tubbs RS, Loukas M, Dupare F. Review of the surgical Anatomy of the axillary nerve and the anatomic basis of its iatrogenic and traumatic injury.Surg \& Radiol Anat. 2010; 32(3): 193-201.

How to Cite this article: Rakate Nilesh S, Gadekar Savita H, Gajbhiye Vivekanand M. Variations of origin and distance of axillary nerve: A descriptive study. Int. j. clin. biomed. res. 2018;4(4): 13-16. 